\title{
BUSINESS OPERATED GRATIS SERVICES - UNDERSTANDING THE REVENUE MODELS
}

\author{
A. KELEN \\ (Received: 12 September 2000; revision received: 15 January 2001; \\ accepted: 12 February 2001)
}

The free nature of the Internet is said to have been lost to business interest. The author contests this claim by showing that the overall non-profit character of the 'net may have been limited but certainly not yet compromised. The best stuff on the Web is still available but hidden behind error messages, unlisted databases, and little-known links. Most of cyberspace is still open for educated research, and serendipity. Valuable content may remain free as long as the emerging online business communication keeps on offering us an attractive compromise in matters of our time-use while on the 'net. This is a tacit give and take but the outcome belongs to the core drivers of the new economy. Online marketing and commerce proceed on a market of clicks - not just users' mouse clicks but also the clicks of third party meters counting time; adding up to statistical profiles; and measuring user behaviour. Advertising can help cyberspace remain toll free by compromising netizens' time but offering something in return for using their personally identifiable data in business operations.

I will track these innovations to the extent of understanding them and will give an evaluation from the perspective of how force-fed or interruptive they are. There are intriguing new initiatives to render commercials less aggressive and more relevant, more predicated on permission and even more dependent on bandwidth. These targeting initiatives promise the demise of the mass culture of advertising as we know it, helping commercial messages evolve into personalised and customised individual knowledge management for opting-in netizens.

This endeavour is part of a wider project to understand further the phenomena of the emerging "Gratis Economy". In this study, I will focus on marketing solutions where freeware is part of a wider revenue model or product selling strategy mix.

Keywords: informational commons, marketing, customisation, personalisation, clickstream analysis, patterns of time use, time budget, profiling, geographic targeting, smart advertising

JEL classification index: $\mathrm{H} 42$

Correspondence: A. Kelen, Faculty of Economics, BABA Program, University of Pécs, Rákóczi út 80, H-7600 Pécs, Hungary. E-mail: Kelen@email.com

0001-6373/00/01/\$5.00 @ Akadémiai Kiadó, Budapest 


\section{FREE OF CHARGE, EXCEPT FOR ADVERTISING}

Most people foster a love-hate relationship with advertising, time constrained people especially so. We may appreciate the fact that advertising informs us about new services - as long as we have our hype-filters in place - and that it keeps the cost of media low, in some instances reducing it to zero. However, we also resent its intrusiveness. We are bombarded by commercial messages - on the sides of buses, on the handles of turnstiles, in restrooms, and at the movies.

There is an intangible burden that is being borne by consumers. In the online world, if an advertisement annoys the prospective buyer, they will switch the site off. ${ }^{1}$ Therefore, the best way to advertise has always been to lure one's prospect, subtly, unobtrusively, professionally, and with a lot of tact. ${ }^{2}$ Online advertising is always trying to distract netizens who are attracted to better content, and are already chasing other information. There is a growing feeling in professional circles, however, that banners are performing at low levels (as measured in click-through, that is, further user activity prompted by the ad) because they are distracting infonauts who have a clear destination in mind. Therefore, the advertising industry's emphasis is turning to targeting the audience with ads that appeal directly to their perceived interests.

This ambivalent state of affairs is apparent on the World Wide Web. The Web is an incredible source of free information partly because of advertising (advertising in its broadest sense of business communication). When radio was launched, it was advertising-free and played classical music to bring culture to everyone. Then advertising agencies developed popular programming to build mass audiences.

1 As the worst abuse of online techniques, I cite the preventing of the use of the back button of the browser as a sort of "trap door URL". Designed to measure clicks and other campaign data, this practice is not only offensive to users but ultimately dangerous to the online advertising industry's well being. Typically a trap door URL directs a browser to an initial page that counts the click and then redirects the browser to the destination page. A click on the back button simply reloads the initial page which, of course, is designed to redirect the user to the destination page. This creates an infinite loop and the only way out is to navigate back through the "go" menu. Your back button is rendered useless. The above practice is very irritating to most surfers. People do not lock the doors behind visitors when they enter physical spaces. This is a practice that trades off long term trust between publishers, advertisers and consumers for short term "gains". The triggered anti-ad sentiments, we know, usually result in a behaviour of not remembering a TV spot after seeing it; of viewers zapping or muting the commercials; of throwing out direct mail without opening it.

2 The advertising industry, relentless as they may seem for most of us, exerts occasionally considerable self-restraint. One example is the well-known "printer friendly" versions of electronically published articles that often do not carry ads at all. Printer friendly versions of website content ensures high quality eyeballs, as presumably someone who prints out an article wants to read the entire thing. 
This sold radio sets and created a big market for advertising. When television came along, the first few years featured announcers reading radio scripts into microphones. It was not television advertising, it was radio advertising on television. It took about a decade for advertisers to figure out how to use this new medium. We are experiencing these formative years now on the 'net.

As to the typology of online advertisements, banner advertisements are the predominant type of advertising, accounting in 1999 for 58 percent of ad expenditures, with sponsorship (29\%), interstitial ${ }^{3}$ (6\%), e-mail (1\%), and all others at (6\%) (IAB Report, 1999). The immense worth of the 'net is in the mass of data and networking opportunity but there - doubling every year. This ever-growing volume of exploitable free information and virtual community empowers infonauts to netizenship. Instead of behaving merely as customers or as victims of commercial firms vying for market share, infonauts have the opportunity to evolve to citizens of an online collaborative and participatory networking society. Netizens are then those who can achieve this advance of network access. As to the definition of an infonaut, I refer to the typical dichotomy of media behaviour. One can watch television for leisure, accepting what comes without much filtering, or switch it on only after a thorough perusal of the guide and a program of interest is chosen. These two opposite media behaviours are manifest when designing a cinema multiplex within a mall, serving people who just browse in shops and drop into a movie whatever genre it may bring about, or the scattered existence of art kinos in metropolitan areas. Parallel to this dichotomy, the Internet has also evolved the pattern of just surfing around without a clear intent, or managing one's information needs. In this latter case, availability alone has little value without a searching purpose and the ability to utilise results. Web surfers occasionally may want, curiously and serendipitously, to be entertained, otherwise - when on a project - a banner is just a blind spot for them. The popularity of streaming media - typical background activities - attests to this. A recent study by Nielsen/Net Ratings estimated that $36 \%$ of all home Internet users tuned in to audio or video streams on the Web. (Statistic quoted from: http://www.mercurycenter.com/business/top/ 049066.htm.) The surfing metaphor seems appropriate: surfers (windsurfers included) are aware of their environment and constantly taking actions to control their experience. Any external stimulus that distracts them from their task at hand can be very annoying, especially if the force-fed information is irrelevant.

Interstitial ads are Web pages usually with large graphics or rich media that pop up between what the viewer is looking at and what they are expecting to get. More like a TV commercial than anything else on the Web, interstitials hijack the control of a user's browser and forces them to watch an advertisement until ad servers feel that they have seen enough. 
Romantic anti-capitalism, the complaints about lowbred commercial intrusions and the desire for escapism is particularly strong amongst netizens (as opposed to consumers in general), as the 'net has only recently started to give way to commercials and consumerism and mass culture. The inception as we know it has been academic (tainted with a taste of martial utility). Everything has come out of government grants or foundation support. The whole Internet has been based on scientists and academics sharing information, collaborating on projects, and posting research papers. Therefore, the assumption - widely held in the business community - that the Internet was primarily an instrument for commerce is still disturbing for many with a set goal while online.

Today, Web advertising is often rampant. On some sites, we find banner ads at the top of pages, block ads down the side and another banner at the bottom for good measure. Pop-up ones may occur, anytime. ${ }^{4}$ There are even ads found on some popular personal home pages and the intranets of the educational domain have also begun to carry advertisements surrendering their traditional penchant to keep commercialisation at bay. In case of content provision, it is a sign of offering endearing mindfulness to pledge that no advertising material will be included on the pages reserved for paying visitors. A less attractive idea is to solicit a fee for the option of suppressing the ad banners that are included on the page. The only content then that is not specifically relevant to the site might be, at most, a copyright statement, which usually appears in small type to be unobtrusive. ${ }^{5}$ Perhaps the best example of a flexible open solution of integrating service and advertising,

4 Larger web-hosting companies sell " 404 page" error redirects. This means that when a surfer on one of the company's thousands of websites clicks a dead link on that site, she is redirected to an entirely different site, a site owned by someone who purchased a certain number of these redirects. The price of this newfangled online advertising trick is a lot lower than what an advertiser would pay for a conventionally targeted click-through, although it is still beyond the budgets of many small publishers. This custom is working fine for the traffic purchasers, even if the redirects are coming from totally unrelated sites. This does not affect the targeting precision because it is the dead links' anticipated visitors who count alone and they can be described and defined correctly. The philosophy is that after a few minutes of surfing users get bored, so when in lieu of a mere error-announcing information - a new, though unrelated site pops up, there seems to be a curiosity that causes the new site to be explored thoroughly. This results in a lot of repeat business. All the hosted sites are usually advised that any dead links on their sites will be redirected in this manner, this practice nevertheless borders on a kind of relentless spamming.

5 Beware of the difference between small type and fine print! Demonstration software products, for instance - that are free to the consumer for restricted use - often offer the ability of the consumer to accept or reject the terms of use. The information, however that might cause somebody to reject download and installation of a product because of arguable data collection practices, or the perceived potential for abuse, is hidden, as a rule, in text format buried in legal language.

Acta Oeconomica 51 (2000/2001) 
is the advancing practice of telephone and Internet providers (for instance "Germany.net") to include a basic-level (gratis in exchange for advertisements) package for consumers. I start to illustrate my point with the description of the revenue backbone of this burgeoning new media of gratis telephony.

The worldwide patent holder is an independent provider of value-added services for the telecom and media industry. They have invented a system that commodifies telephone interactions by input of commercial messages and information during a call, so subscribers can call free. The service for the residential market of local and distance calls in fixed and mobile networks was first introduced to the (Swedish) public in 1996, and the company intended to become a global actor around the world. For the first time people had the opportunity to make phone calls for free if they were prepared to listen to commercials every second minute. The service enabled the caller (A) to make a free call to (B) and in return, both parties (A) and (B) will be fed short commercial breaks of ten seconds during the call. The system is said to be flexible and to have various constraints as to the length of commercials, intervals and total call length. When becoming a subscriber, consumers fill out a lengthy questionnaire inquiring about their age, gender, household, interests, habits, etc. This enables operators to provide (A) and (B) with different messages in real time due to each member's individual sphere of interest. If a non-member (C) is called by (A), ad tailoring and selection can of course proceed based only on time and geographic area. Sponsored telecommunication along this patented line is predicted to grow, with licensees world-wide promising the media market a unique way to reach consumers with 100 percent attention and targeting precision, ${ }^{6}$ and measurability. ${ }^{7}$ If a licensee is an existing telco, consumers may be offered the option of choosing between full cost calls and commercially sponsored telephone calls. This foreseen level of consumer choice approaches what can be regarded as a seamless transition between high-end and gratis services.

Beyond telephony, this business gambit has also found its way into Internet-service provision. In an effort to both ride the wave of free Web access and actually make money on it, Internet-service providers are offering subscribers discounts for watching ads. They supply unlimited access as long as customers provide personal information (the disclosed information supplemented by derived

6 As to the dissemination of commercials, the profession keeps on contending that one half of their budget is usually wasted, due to the missing precision focus. Unfortunately no one can tell which half...

7 The salient indicators to be measured are return on investment (ROI) and click-through rate (indication of closer interest at the prompt of an ad) and conversion rate (resulted purchases from an ad). 
navigation habits of unsuspecting users is occasionally being passed over to networked advertising partners such as auction houses, matchmakers, and booksellers) and put up with targeted (less annoying) advertisements streaming to their desktops. If customers shut the ad window, their Internet connections are cut off. There is a new feature called the Surfree Surfbar, an ad window is built within the browser, and as long as subscribers keep this window open, they will pay less for their monthly access fees. The longer they put up with the ads, the greater the discount. If they close the ad window, they begin paying full price. Ad revenues are passed on to the user, which becomes an advertisement subsidy for Internet access. As a third model supplemented by gratis Internet provision, gratis $\mathrm{PC}$ provision in return for force-fed commercials, this revenue model can also be construed as one helping consumers to behave rationally in relation to advertisements.

Freebies serve people who are ready to trade time for money. Most people if not all are like this. To clear up possible misunderstandings, freebies are by no means 'junk' products, even if the classical sociological definition of 'junk' may apply: "Junk is the ideal product ... the ultimate merchandise. No sales talk necessary. The client will crawl through a sewer and beg to buy... The junk merchant does not sell his product to the consumer, he sells the consumer to his product" (Burroughs, 1986). Freebies are rendered free, not by their intrinsic qualitative nature but, rather, by their fitting into an objective marketing strategy, not necessarily divulged to consumers. Even if freebies are not 'junk', they are meant to satisfy thrift and enable our economising with time. Some people overgain themselves by sacrificing due leisure, they are certainly not clients for freeware ${ }^{8}$ - from a frog's perspective this might be called the Concorde-phenomenon. Others with much slower taxi-meters cope with often sophisticated and time-consuming strategies of self-servicing because of their sagging capacity to generate enough disposable income. Thus self-help is always a buffering counterbalance to time selling, that is money earning. People vary in the spending of their time-budget as much as in other dimensions of assets and inequalities. There is an entire sociology behind this single issue: who is ready to give time for money and, vice versa, who is interested in saving time at the expense of spending more money.

Whereas voluntary timesharing and intentional job-sharing serve the upper one third of our two-third society, gratis solutions of the off-line world are meant more for the lower $2 / 3$ down the road toward the active poor or even the "laboriously idle" or the alternative scene. As for the online world, the Web is in the making for

8 A certain amount of status discrepancy causes many people to go for freebies even though they could afford to side-step. 
the entire middle class. ${ }^{9}$ Net-powered young consumers are incorporating the 'net into their lives as intimately and instinctively as older generations have embraced automobiles and television. Therefore, its multiplying free solutions carry less distinguishing social character. This is the case even if boons and free loot draw the interest of younger strata with less purchasing power. I think it is safe to assume that in the foreseeable future (NSTIA Report, 1999) everybody (in the middle class + the active poor) will have an e-mail address although this alone does not mean the bridging of the informational divide. (In a later phase, a wired household will have all its processor-endowed gadgets carrying their own IP-address.) With faster Internet connections becoming more widely available (with the worldwide adoption of the deregulated American telephony practice of flat rates in local calls instead of charging by the minute; and making Internet access even more user friendly, like 'voice steering' of computers and the onslaught of wireless Internet), we may soon witness the maturation of the information society. By then, the 'net may cease to be a tertiary medium on its own, instead there will be several media such as, a PC monitor, printers, personal organisers, speech synthesisers, but also digital cameras, MP3-players and cellular phones that will be used to access the Internet as the interoperable arch-medium.

In summary, I have tried to consider the indicated trade-off between rendering something toll-free in exchange for time use. The duration spent by the perusal or glimpsing of an ad impression is not negligible. The amount of this audience's time elicited by media owners is currently by no means flexible enough - their market is by no means complete. As a rough classification, there are cost reducing ads (most newspapers, most broadcasting, most media carrying high culture), enriching ones (TV, sports) and the grey zone between them, which is blurred against all marketing surveys. We are fed ads not merely to the limit of covering some costs in either media, no, we are given always as much as we can take, or as much as the size of paper can carry, or media regulatory authorities permit or the media owner can garner. This is only parallel to the ubiquitous fact that the rankand-file usually earn as much money as they can without deliberating a healthier or laxer trade-off between toil and leisure. I am compelled to state this lack of due flexibility, although flexibility is much easier to attain in online advertising than in any other field of business endeavour.

9 The biggest reason Web advertising continues to explode is that the emerging demographics of the Web look increasingly like those of the rest of the world. The Web is attracting a significantly higher percentage of women and middle income users than before, opening opportunities for publishers and advertisers whose products are completely unrelated to computing or the act of surfing the Internet itself. 


\section{TARGETING}

There is a valid place for accurate targeting in the sense of invalidating the old saying "half of advertising works and half does not, now if we only knew which half works". But diplomacy and common sense can still teach us something: if someone relates to me I might think he or she is perceptive as a friend; if he or she relates too well, I might suspect an agenda. In the ensuing pages, I describe methods of technology-aided targeting that the Internet, as the newest commercially exploitable media, can offer. At the same time, I will try to visualise the privacy-related outer limits of online targeting. Improvements in marketing could reach a level when the time spent seeing ads was not a deduction but an added value for viewers. The targeting of advertisements could only be fully personalised if Internet service providers and advertisement server owners were allowed, in their profiling endeavour, to maintain a personalised database of purchasing (and searching) habits. What media owners can and often attempt to do is to build as many subgroups as possible, and cluster each incoming call at their server into a specific profile, and smooth over any differences in age, habitat, school attainment, occupation, etc. This adjustment may represent a great step forward in advertising techniques and an honoured relief for prospective customers. ${ }^{10}$ The techniques of geographic targeting offer the capability of selecting ads for specific geographic areas. Geographic segments available include city, state, ZIP code and area code. Advertisers now have a greater variety of options (including geographic targeting), which allows them to customise media buys that will have the greatest impact and offer the best return on their investment. While searching in AltaVista for instance, European surfers are already fed regionally relevant and culturally more fitting information in their own language.

As targeting is predicated on data management, its development is contained by information privacy risk considerations, and as long as the governance of the 'net remains as it is (sort of organic grown freedom), there will be no unified and impregnable privacy policy across the star-dust of sites. What is more, the marketing information at a time preceding my intention to buy a car is information very limited in topicality. Therefore, marketing information on customers, ought to be not only relevant but timely as well. Such a magnitude of management of data by media owners or by anybody else is inconceivable without (self) regulation.

10 Educated consumers may like ads - we are told. But even educated and choosy consumers may want to draw from independent sources, too when preparing for a more decisive purchase. For average consumers then, let alone those with an anti-consumerist stance advertising is rather a necessary burden tapping their precious time. And, as the wise Hungarian saying holds, time is always too precious to squander it for cheap whines. 
The marketing-driven progress of the online world is advancing by devouring millions. As technological innovation is centering on the Internet, cyberspace is a "happening" place, and it is easy to lose sight of the forest for the trees. It is still safe to state that in the case of a website, for instance, the "eVertising" industry's threshold of business interest starts at millions of impressions per month. The generation and attraction of mega traffic has always been the underlying motivation of media owners, similar to the behaviour of an owner of a highway. The aim is always to generate traffic like a railway station during rush hour. The outcome of such traffic is called "portal power": owners of large number of users can use those relationships to extract rent from others who want to reach these users as customers. In this regard, cyberspace is just the following edition and re-enactment of mass culture, as we understand this concept since the cultural prophecy of Ortega y Gasset. This course of events is parallel to the commercialisation of the 'net that may have "degraded" the erstwhile academic and therefore unashamedly elitist content of cyberspace into mass culture. Coupling this new mass content with "webvertising" precipitates this trend of popularisation. The current situation can be likened to the era after the invention of printing when priests - the former managers of hand-written books as to their creation and dissemination was concerned - became vigilant with resentment of the emerging businesslike printing guilds.

Enhancing the targeting capabilities of business is parallel to its globalisation. Parallel, but in the opposite, countervailing direction. Even though the Web makes every site global, the need for discrimination becomes stronger. Improving focus is logically tantamount to localisation, and local recognition. Practically, though, it is somewhat different: whereas localisation has an inherent meaning of regionalism, language and nation, marketing segmentation and marketing focus can easily cut across these dimensions and lump together people, not according to their location, but according to their interest or taste or revealed preferences. Personification creates virtual personalities. Localisation creates mostly somewhat adapted translations of similar content. Additionally, whereas globalisation is tantamount to being unregulated (by state authorities), localisation does not necessarily surrender customers to control. Segmenting the clientele into smaller and smaller groups, reaching a satisfactory level of personification, ${ }^{11}$ is an important counterbalance to a global outreach. Targeting is then amongst the new localisation factors businesses usually seek to strengthen their local ties and citizenship.

11 When applied correctly, personalisation becomes the antidote to the outdated concept of undiscriminating, mass marketing. It becomes the answer to the approach of Henry Ford, who was said to remark after introducing the Model $\mathrm{T}$ that customers could choose whatever colour they liked as long as it is black. 
Lumping together an audience for millions of impressions generates the mass culture. Localisation alone will hardly break that. It is, rather, targeting that promises to attain this break. The 20th century has witnessed the unfolding of mass technologies from mass consumption through mass culture and mass entertainment. I refrain from continuing this long list. At the same time these millions, once acquired by a media-czar, are undergoing detailed socio-demographic analysis to create smaller and smaller clusters enabled by the data depth. This often results in niche marketing, a distinctive feature of the targeting capabilities of online advertising. Thus, there are two prerequisites here: the simultaneous upholding of technological standardisation that strives to create a mass audience, and the on-going promotion of diversity that discerns them according their marketing traits. This is the ambiguous development path of the online media from a cultural perspective. I think, at the very end, these presuppositions forebode the dissolution of mass culture, as we know it.

The Web may be a great tool for customising messages; pinpoint targeting of ads to the correct, receptive audience; making way for direct interaction with the provided consumer; and creating evidence based data-driven customer relations. Actually, evidence based online advertising with its emerging tracking technologies is a substitute for traditional off-line survey methods, interviews and questionnaires.

Concisely, I describe a tracking technology - rough as it is yet. Clickstream analysis is a page-by-page tracking of people as they surf through the 'net revealing preferences and interests. Visitors "reveal" their interest by conducting queries, choosing from directory listings, following link paths, carrying out keyword searches or by exploring particular subjects. Aggregating these navigation facts and "learning", the likely responses and the underlying motivation behind this behaviour is tantamount to creating a user profile. This sort of artificial-intelligence-generated dossier enables advertisers to leave behind general buys, and target ad campaigns to consumers classified into specific behaviour groups - such as entertainment seekers, business seekers, real estate seekers, etc. - by pinpointing characteristics and interests drawn from observed and registered navigation and click-through pattern of each visitor. With this knowledge of evaluating profiles ethically, only anonymous profiles, ${ }^{12}$ which do not include things like names or

12 The Federal Aviation Administration in America recommends that airlines use computers with profiling software to identify suspicious passengers instead of relying on airline personnel. The software was developed with a Federal subsidy, and most major airlines have been using it voluntarily since January 1998. The F.A.A. will not reveal most of the criteria used by the software, but one of them is whether the passenger paid cash for a ticket at the last minute. At the prompt of civil liberty groups, the Justice Department, privy to the criteria, ruled that the criteria 
off-line addresses - carried out always in real time, the expert system can predict likely responses and re-direct ads or change their creatives, delivering them only to the people most likely to respond. When ads are delivered to visitors most likely to be curious about what is on the other side of the banner, the all-important click-through rate can be optimised. This enables advertisers to adapt media buying money to "audiences that count" with enhanced relevance. ${ }^{13}$

This state of affairs with profiling and effective ad-targeting may portend the approaching end of mass communication in electronic advertising, but will certainly not bring about the demise of the "excise" character and interruptive nature of commercials. Ads will keep drawing on our time ${ }^{14}$ and we can only be happy if these ads - now an outcome of the observation of our cyber activity - convey a chunk of timely or relevant information to us. Artificial community building based on objective criteria reminds me of holding a mirror by some unbiased observer. Mirrors are neutral and can often yield unexpected results that are difficult to digest subjectively. If ever we were confronted by our prepared virtual club-membership - being ranked and classified by a neutral expert system based on garnered results of our earlier surfing record, search engine lead words and revealed choices of taste and affiliation - only few people with accumulated life-wisdom would tolerate or accept this sort of experience rating. It is unsettling to most people to have their minds apparently read. All too hastily we are all inclined to suppress into oblivion our light hearted inducements that cyberspace easily allows us to fulfill, such as reading horoscopes, playing the lottery, or 'scarfing' down the occasional pint of ice cream while watching a soap opera.

were not discriminatory and eliminate "the potential perception of personal biases". Also, the computer can juggle more factors than a ticket agent can, and if the criteria are computerized, they will be easier to keep secret. The airlines have generally accepted predictive profiling, which is integrated into their reservations computers. On domestic flights in America, the bags of passengers who meet the profile are either scanned for explosives or are "matched", meaning that they will not be carried on a flight unless the passenger boards as well.

13 These proprietary technologies are well in use, deployed to the screening of some daily 160 million credit card accounts to detect possible fraud. As to enhanced click-through rate, the pilot phase of a product demonstrated a rate $25 \%$ higher than achieved by conventional purchased keyword targeting. As to relevancy, there are no sources or qualitative data because mistargeted consumers do not complain.

14 I quote from the narrowband ad guidelines of the American advertising industry. Ads ought to be "consumer-centric"; technology should play a supporting role; the goal is :05 - :06 second ad unit download based on site's predominate consumer connection speed. What advertisers basically expect from ads is of course positive sales results. Agencies translate this expectation to (1) brand imagery and recall, (2) interaction within the ad, (3) comprehension and liability, (4) provision of effective branding experiences, (5) engaging viewers for a longer period of time, (6) offering lower cost-per-branding impression (CPB). 
At the same time, if requested, profiling businesses (such as genetic profiling for experience-rated private health insurance) cannot deny consumers access to their developed virtual personality, even if this development proceeds in real time and will not be stored as petrified personal files. Using memory-less machines and Hidden Markov Model techniques, predictive profiling uses inter-session visitor information without keeping a record of users or IP addresses. Some sort of $\log$ files or cookies of course, must be at hand accruing and storing a visitors' navigation record. To keep track of visitors who return to their Web sites, operators place digital tags, or cookies, in files on visitors' computers. Web sites can use cookies to help them track visitors' movements across their Web sites, but usually do not know who is at the PC on the other end. Nevertheless, many sites also use advertising-service companies that place banner ads on their sites. Those companies, too, send Web surfers cookies or create session variables so they can keep track of which ads they have seen and which they have not. Since the ad networks want to maximize the effectiveness of the ads they place for their clients, they send Net users ads that correspond as closely as possible to interests they have revealed through visits to other sites on the ad network.

From a sheer businesslike perspective, I can even imagine that hermit-minded users insisting on self-determination may rather want to furnish advertising providers themselves with their self-made profiles that are more apeace with their souls. However, the deployment of an artificial intelligence ${ }^{15}$ cannot be forgone here: this is potentially a genuine added value that cannot be substituted by asking consumers to submit ad servers their preference list, or assumed profile, even if most privacy problems could be bypassed except for the vicissitudes inherent in handling personal data. For instance, the location of the target audience can provide publishers and advertisers with some modelling through lifestyle segmenting codes that can predict what "type" of people live in certain neighbourhoods. This so-called precision grid gets down to what kind of beer neighbourhood inhabitants statistically prefer to drink. A "lifestyle segmentation system" defines every neighbourhood in terms of demographically and behaviourally distinct clusters. It may link with major off-line marketing databases. These links make it possible to use it for a wide variety of marketing applications at the national and local market level, from media planning to database marketing.

15 Another widespread example for the deployment of artificial intelligence in media: a typical added value that distinguishes a mere TV coverage from an edited program is the use of digital imaging in the backdrop. This has long been a widespread practice when covering sports events and trying to show different decipherable ads from the background. Recently, newscasters experiment with digitally inserted images but this cannot be accepted as good media practice because it adversely affects credibility. 
There are simpler and more sophisticated means to render an ad relevant that is less interruptive. The simplest way is to advertise on a site that is squeaky clean having limited editorial links. The more "links" are offered to the people to click on, the more "opportunities to click" are spread out to both advertisers and content. Sites today have over 200 links per page! It is no wonder that these publishers are not getting more than $0.5 \%$ click-through rates.

There are several examples of sophisticated technological developments that affect the occasional obtrusive character of ads through managing the main patterns of time use in their consumption. ${ }^{16}$ Many of the marketing devices that businesses use online have a parallel off-line: personalisation, database marketing, predictive profiling, up-selling, cross-selling, limited time offers, free gifts, coupons, entries in sweepstakes, rewards and a whole lot more. Nevertheless, in the hurry to recreate what works off-line, it is easy for marketers to ignore what can work only online. This unique feature is the specific time-relation of cyberspace. If trying to define what is the definitive essence of the Internet, there is no other differentia specifica than it is us who choose the time when to access and when to drop a connection. In addition, one thing that is unique to direct marketing online is that we can control the time that our e-mail is delivered. Off-line, we are always at the mercy of whatever postal service we depend on. In some countries, we can be sure at least which day our message will arrive. In others, the guess could be days off either way.

Concluding the description of the emerging new online advertising scene, I point out that online targeting is a promising trend in business communication trying to render commercials more relevant. In perspective, this trend may terminate the "pushed" and mass-cultural features of advertising, domesticating them into a tool of personal knowledge management. This quest towards evidence-based, therefore "smarter" adverts, fits into the wider trend of applied precision in smart drugs (genomically targeted pharmaceuticals with predictable patient-response eliminating the very notion of "side effect"), smart bombs (without collateral damage) even smart sanctions (hitting rogue officials instead of the population). As to the currently adopted mechanisms of targeted information serving, I can only express reservations. A plethora of start-up companies in the new economy currently work at being able to display targeted (occupation-specific; industry-specific; age-specific) information (text and ads) to visitors on a website. As

16 I must refer the interested reader to my forthcoming book (Kelen, 2001) where I furnish a thorough evaluation and technology analysis embedded into an examination of whether (first generation) precision technologies will ever bring about the demise of mass communication and mass marketing. 
judged according to its maturity and relevance, this first generation design can as yet be likened to the - rough as they are - tools of brain science, observing the energy consumption of locations within our brain and theorising with the linkage of this experience to behavioural observations as discerning, distinguishing, etc. This is as crude a level as trying to guess what a family is doing within their apartment by observing their meters as the household consumes electricity, water and gas.

\section{VALIDATION OF BUSINESS COMMUNICATION IN CYBERSPACE}

From the perspective of seeing ads as the opportunity cost of purchasing an entry into a website, I devote much attention to the chances of rendering ad impressions less obtrusive, interruptive and more relevant. There is, however, an inherent problem when deliberating the chances of a change in the nature of commercial communication similar to the domestication of a black panther into a pussycat. I refer to the old problem of the often-dubious validity of advertising content. I am not necessarily speaking about deceptive practices; I merely remind that commercial messages are designed less to convey an informative content than to stir desire. Therefore, they do not even try to be objective - this is not even within their vision. Ads are nearly always predicated on some degree of gullibility.

Banner advertising is still a decent form of commercials compared to the following genres. When installing software on a computer we are often confronted with an icon placed somewhere on the task bar without permission. When installing a free Internet related product it can put some moving graphics easily and automatically at the top of the browser directing the user somewhere. When going to a site, often it starts using up the computer's speed and memory and throws windows at the user that confuses the concentrated navigation task. These examples are like watching a movie on TV with advertising coming on, and at the end of each ad the advertiser ringing our home telephone to ask if we are interested in their product. Moreover, the only way to stop the ringing would be to pick up the receiver and then put it down again.

I doubt that the victimology of advertising would change with the onslaught of the online world. The invocation of yearning desire is an inexorable part of advertising. Perhaps outright rip-offs (especially in investment solicitations) may phase out with profiling. Well, this uncompromising invocative character may never cause a problem as long as consumers do not act as infonauts and do not take commercial messages for information. The 'net as operated increasingly by business has an inherent inclination to hide or veil corporate interest and neglect truth for 
publicity. I give a summary of concerned methods in order to weigh the pros and cons of whether personalised information management (the cat) ${ }^{17}$ is a feasible goal for the current practice of selecting and targeting advertisements (the panther). As centring on the cutting edge of technological development, traffic attraction and especially targeting are sheltered business secrets of the industry. (Another "trade secret" of this baby stepping new industry is that ad-space owners count figures and third party measurement rarely concur in the chase of Web traffic.) By dynamic targeting, I mean well-segmented, perhaps even one-to-one targeting of 'net content with strict privacy controls and total confidentiality or anonymity.

The right online marketing and promotion will certainly enable customers to find a site easier when they are searching for the products or services. Search engine positioning will make or break an online business. However, in return for a "slotting fee" there are also trickier methods to grant a preferred position for a paying site, to enhance their visibility. These methods apply tools that advantage paying sites to the detriment of others. The ranking criteria can thus be permeated by sheer selling interest. ${ }^{18}$ In summary, Web advertising and customised e-commerce applications are to be viewed as methods of establishing trust and an on-going relationship with a customer. This is a process in which both entities try to figure out if they have found the right partner: did the publisher choose an adequate commercial and did the users visit the right place that satisfies their hunger for information. Much of this conversation - the interaction between data collection as evidence gathering by the content provider and internal navigation by the user - is about iteratively figuring out what customers need in information. Knowledge management of this sort is the art of maybe.

These are some particular cyber ways and means of acquiring unprecedented publicity. Cyberpublicity that is making brand names known and products avail-

17 For example, a New York site offers an extensive database of brokerage research with a powerful search tool. Instead of just advertising these facts in the banner ad, they place ads on the search result pages of financial sites and pose the question to the user who just searched on a ticker symbol for say, "AOL" - "Interested in brokerage research on AOL?" By offering information to the user on the very ticker symbol she had been looking for information on, they have provided her with an "offer" that directly links her to the content she specifically wants. To make this one work though, they must link the individual who clicks on this ad to the content on the site that answers the offer, not just to the home page.

18 Contrastively, an example of search engines with proffered content-neutrality is the intriguing project of Eurogatherer. This will be a personalised information retrieval system that sets out to search (and internally translate) in a multi-language environment enhancing enormously thereby the visibility of smaller national cultures in Europe. 
able worldwide is as much a precious and scarce good as any other source of publicity. Here is a brief description of how reputation works.

An audience is the ultimate resource. A publisher's product is not only content but also its audience. In the traditional media, the audience is perhaps the genuine product. Advertisers purchase access to an audience to sell something. In this process, the size and the quality of an audience are of equal importance. If the advertiser makes an inadequate pitch or prepares some poor creative then the audience will not be addressed with success and the resource is being wasted from the perspective of business communication. Reputation builds off of attention. Attention of interested people is a unique resource of the human condition and an underlying driver of societal forces comparable only to power. Empathy is one of the most coveted accolades a beloved can offer. Attention is the operationalised form of empathy reaching far beyond the intimate sphere. In modern post-industrial societies with wide affluent strata, our attentive time is even more scarce than money. That is why reputation (the accumulated form of publicity) makes wealth (the amassed form of money) look often sombre. Some people and some organisations receive unsolicited attention; others pay for their visibility. The latter is called advertising.

The Stoic philosophers and the followers of Epicure dissuade us from the vanity of following the path of prominence; their advice is to hide from the world. Celebrities also often complain of the backlash fame brings about and prefer to keep rather a low profile. However, as the philosopher Kolakowski (1998) wittingly remarked in his concise lecture on fame, one can hardly believe this reservation because stars chase media attention with all means.

Publicity builds from attention just like money is petrified toil. Publicity, the accrued quantity and crystallisation of attention is a desired commodity that constitutes prominence, one of the modern equivalents of noblesse. This commodity of attention-related income is produced by the media constituting a virtual market of vanity (vanity because the coveted esteem of attention is always personal but the one actually granted is mostly alien and businesslike). One can nevertheless milk fame, feed and grow upon public attention. Celebrities' "attentive" revenue feeds on their attraction potential to be exercised in the media - the Internet notwithstanding. ${ }^{19}$ This potential is amply rewarded by the market: some investiga-

19 This could be the sole consolation for copyright-holders whose intellectual property is increasingly infringed upon by cyberpunks using disruptive innovations such as MP3 music recording technology. Cyberpunks, or romantic anticapitalists consider copyrights to be the usurpation of an inherently collective good. The advantage to be gained from the exclusive utilisation of a copyrighted item is going in the cyberworld to transmogrify into gains to be derived from publicity. The spreading phenomenon however, that sites draw attention by 
tions even speak about "Winners Take It All Societies", referring to a definite skew in income distribution to the advantage of superstars picking up the lion share of available income in a particular business like research, medicine or showbusiness. Further examples for this trendy expression: there is no coalition government in the USA, the winner takes all; whereas in the European Union there is no political majority at all, there are only political, national or ethnic minorities. This "businesslike" iron rule also applies to online advertising. In this rapidly growing business segment the top $50 \mathrm{Web}$ publishers reap the overwhelming majority of ad money, accounting for 95 percent of revenues for ad-supported sites in the U.S. in 1999 (E-commerce Times, 1999).

Fame that has been once attained by deeds or virtue is nowadays tantamount to media exposure. An income based on fame could be drawn long before modern media emerged but the media has multiplied this resource of social distinction. A slight difference between accumulated wealth and stored-up public prestige is that the origin is by far not indifferent. One cannot derive genuine prominence from publicity among people of dubious value! This is called messalliance. "Attentive" income leads to prominence only if it can be attributed to the attention of people we can accept or even honour. Just like our accompanying persons or entourage (or recently the domain of our e-mail address) qualify us ourselves. This qualification creates a sort of "exchange-rate" of publicity.

In addition to fame and publicity, there is imitation as a further source of attention-generated prestige. This is experienced among the software developers of the technical community of computer programmers, especially within the opensource software community, where the shared heritage of all practitioners can also elevate and acknowledge talents. In their world without proprietary roadblocks to innovation practices (such as patents) imitation is a flattery. In the very end, of course, when all arguments are said, it is dignity alone that humans are endowed with, never value.

Contents are mainly subsidised by attention-devouring solutions such as advertising or by the marketing utilisation of acquired personal data. Search engine sites are increasingly presenting users with a mix of relevant and sponsored links making relevant searches with human judgement somewhat more time consuming. Thus, the input in this bit-driven segment of the economy is commodified per-

offering copyrighted products as freebies cannot be seen as romantic preaching of de-commodification - this is sheer business. There is no clear-cut distinction between what is the legal domain of copyrighted products and collective goods: there can only be a balance. For instance, value added information created in public administration certainly belongs to the commons although the ownership of such a database could generate ample income. 
sonal data or time. ${ }^{20}$ Actually, this is possible because time is only a proxy for attention.

If a Web site is not attracting traffic and pitching the sales that it should, it is likely that it is not visible enough. That is, it is not ranked well on the major Internet search engines. According to recent Internet E-commerce studies, over $90 \%$ of consumers - only a subset of surfers, of course - find the Web sites they visit by using eight major search engines, which are Yahoo!, Excite, AltaVista, Infoseek, Lycos, Web Crawler, HotBot, and Northern Light. If a website is not located in the top-30 listings of these engines, chances are the site will practically never be seen. Most people never get beyond the first few items at all. The single most important thing one can do to increase a Web site's traffic is to increase its search engine ranking. Of course, the (tried-and-true) search engine ranking is only an indicator. ${ }^{21}$ What really counts is how fast, fresh and easy the site is to use. How does one's Web site compare to other sites in the same market category? Objective web-site benchmarks are therefore an absolute must for an online business. Unfortunately, this distinction between virtual and actual reality, appearance and value has never been characteristic for marketing.

Until greater accuracy is achieved, content on its own will only rarely excel in cyberspace - auxiliaries are thus administered to help them achieve reputation. This is perhaps no different in the off-line world either! The vintage search engine AltaVista was first to give preferential treatment in search results to those who pay for their listings. Yahoo soon followed suit. This contrivance has brought about the onslaught of other pay-for-position search engines.

There is an alternative revenue model for pay per-click engines. Before its termination, MSN's keyword program was also to bid on specific search terms. Unlike Goto, the auctions ran for about a week. One would bid on a monthly cost. Each week, the highest two bidders would win and be charged for one week's worth of their bid. A week later, their site would be listed on the left-hand side of

${ }^{20}$ Being cheap is achieved (or rather approximated) through advertising in all mass media. Ads definitely slow down the process of consumption. Commercials expend the limited time of TV watchers, too. Prime time is then more valuable than average time in all electronic media. Thus we can draw the conclusion: the time equivalent of the input in this segment of the economy undergoes as close scrutiny here as any other scarce resource in the overall economy. This is only possible because of it being a quantifiable continuum.

21 To illustrate what some indicators can perform, let us see the explanation for the stock market value of hi-tech firms. The more popular the site, the higher its "ranking", the more the company is worth. Just like in high school: Web sites with the highest valuations are like athletes or media stars, whose top-of-the-chart popularity ratings give them far greater currency in the social order than, for example, the shy, geeky nerds who may excel in art or science. The digital economy is a popularity contest. 
the search results under a section called "sponsored links". By giving the winner a week, the auction was less intense than at Goto.com's where advertisers can get bumped literally minutes after they aggressively bid towards the desired rank. In the Goto model, someone can bid immediately against the former advertisers for the top 5 or so positions, just to knock them out of those spots. The click-throughs on these promotions were extremely low; people almost never clicked on ads placed on the left-hand side of the page.

In an accomplished model, engine operators will not show bidders who the top advertisers are when bidding. Approved merchants (editors review every submission for relevancy to retain a minimal degree of credibility for their search engine) are simply bidding for a ranking position, not to eliminate a specific competitor from a spot. This accomplished model then lets users monitor the clicks their placement received, but they are charged only to be online for the week. Unlike Goto, advertisers can earn an unlimited amount of traffic.

Nevertheless, let us not confuse "personalisation" with "customisation". The opportunity for personalisation has always been there; having someone knowledgeable to answer a consumer hotline, or responding quickly to consumers' letters. What the 'net promises to allow is a deeper and richer product story to be told to those consumers who have been already "seduced" by brand awareness generating mass communication. Used appropriately, it also allows consumers to feel that they are interacting with their brand. This may certainly build loyalty. However, in order to personalise this relationship, personal intelligence and personal interaction is needed - customisation is not equivalent with personalisation. Medical shots are beginning to be personalised to the extent that one's immune system remembers the encountered bacteria - this is the utmost in personal treatment. I think that the data-driven advancements of online marketing promote customisation. Cyberspace through customisation becomes truly valuable as an avenue of two-way communication.

An inexorable criterion is that marketing should never conceal its essence. Hype can best be dispelled if content and advertising are kept separable. If a search engine sells keywords or gives preferential treatment for paying clients, this practice should be clearly announced. "Page optimisation" ought to be constrained within limits if the search engine does not sell all the keyword placements as a default. Nowadays search site promotion is considered a tactical success for an advertising agency in giving added value for a client. ${ }^{22}$ The norm of separating

${ }^{22}$ Here is a concise summation of how agencies try to add value for a client as to keyword positioning. In their view search engines can be one of the most cost-effective channels for new business if the web site is positioned properly. Unlike the offline yellow page directories that are 
content from advertising amounts to drawing a line between the gratis and non-gratis domains of the economy. Sub-rosa marketing campaigns ${ }^{23}$ are not only a serious obstacle for all infonauts, they create the potential for a sort of "information pollution" on a scale we have never seen before.

It is necessary for emancipated netizens to be able to distinguish between advertisements and content. The pragmatic adaptation of this maxim depends on internalising the following criteria: (a) Information is everywhere. (b) Personal information has a particular value. (c) There is such a thing as a free lunch but it is advisable to understand what makes that specific type of gratuity tick. (d) Building trust does not require face-to-face interaction. I think the above described skills and criteria qualify netizens to due enlightenment and rational choices in issues of online marketing. Enlightened netizens, on the other hand, are necessary preconditions of exploiting the covenant of cyberspace: a virtual society where all activity is traceable, measurable and recordable. In matters of the sociology of online marketing, these lofty tenets boil down to prepare ground for the transmogrified advertising business. As mentioned above, commercials in the end are in the process of turning to custom-tailored personal solutions, blurring the border between advertising and information. Ultimately, ends should meet in the post-modern consumption of advertisements and the precision management of our privacy needs, too.

Online marketing's philosophy is utterly distinct from all other media: the ability to monitor user patterns and online user behaviour with pinpoint accuracy, and then respond to them, custom-building each users' experience. The convincing tenet is that no one dislikes seeing an ad for a product they are interested in. A well-targeted banner with clear unambiguous and compelling offer usually gets

very costly for a text-based listing, the search engines offer international exposure and cheaper listings. Agencies find that a well positioned and optimised web site can generate significant "qualified" traffic and sales transactions, given the web site offers a product of value to the consumer. For clients they provide a suite of search engine services consisting of: 1) hand submissions to the top $50+$ online directories until the site is listed within the proper categories; 2) development of customised doorway pages that are hand-submitted and optimised within the top 18 search engines; and 3) purchase of the top listings on the "Paid For Listing" search engines such as Goto.com, FindWhat, and others. Further on, agencies also research competitor links across the Web to identify significant cross-linking opportunities.

23 This applies to what is called viral marketing, too. One element of viral marketing is responding to threads in online discussions and newsgroups. Another is "seeding" discussions in such venues. In either case, participants in such venues do not expect the venue to be "used" by merchants. 
the click-through. ${ }^{24}$ Clever graphics, misleading or teasing messages may get a higher click-through rate (CTR - the user retention of an ad) as indeed does rich media but that does not necessarily make them more effective. If the ads that are served are customised, highly targeted, and perhaps even requested by the consumer, CTR will increase, which will benefit the advertiser. What matters is what happens once they get to the site. Misled people simply convert to rapid back outs from the advertisers site. In fact, personalised, one-to-one advertising is flattering - much like re-visiting the nice old hotelier who knows our name and what we like to eat. Moreover, the user is not the only winner: marketers and retailers increase their click-through-to-acquisition margins, plus a wealth of ultra-specific demographic data.

As an epitome, I claim that bespoke-marketing software packages are still a rarity to deploy. In addition, there is no industry-standard package yet for monitoring user tracking from click-through all the way to fulfilment. Complemented with these two pending innovations online business communication will transform from the muddy world it is now to an evidence-based precision business what is more, a scientific (mathematic statistical) business with a bit of old-fashioned human warmth. These online initiatives may bring the industry nearer to delivering on the old entertainment business philosophy: if you do not like what you see, turn it off, do not patronise it and eventually, the market forces will repress the flawed initiatives.

\section{COMPETITION POSED BY GRATIS SOLUTIONS}

Gratis services are a tacit cover of unexpected competition within the overall economy. Few businesspeople complain, for instance, about the competition posed by volunteers. This enmity, however, occasionally exists (let me refer to the woes of English teachers in Hungary at the arrival of the American Peace Corps English teachers in 1989 in the wake of sweeping regime switches in CentralEastern Europe). The independent voluntary sector has gained acceptance all over the Western world together with its fund-raising techniques and grant-making foundations. That part of (language-tutoring and other) business that may have been hurt by this unexpected competition has long since changed its business approach.

24 There is a personalised e-mail news service that provides its members with brief "Minders" to provide expert help in the areas of family, entertainment, autos, personal finance, personal events, home, yard and garden. Because its messages are precision targeted, the company has achieved response rates as high as 45 percent. Untargeted e-mails usually generate 1 to 2 percent click-through. One key element to successful e-mail is to have relevant content. 
One eminent victim of the newfangled free trade, generated by gratuitous services in cyberspace, is the music industry. On the Internet, files are easily copied and shared, whereas physical CDs can only be borrowed or traded. With millions of people with some 50 billion circulating rippable CDs in their possession electronically connected through a centralised directory like MP3.com, the sharing becomes easy. Corporate holders of conventional intellectual property look in the perspective of this enabled new free trade increasingly like unmerited monopoly holders. Label companies are urged by business analysts to embrace the new models and increase their chance for survivability and success. Musical artists are advised to switch to making more money from appearances, sponsorships, and product licensing than from the sale of the actual music. Advertising is ceded to play a role, as may new business models such as subscriptions to electronic distributions, but - we are told - we may even find that artists can deal directly with consumers via the Internet, bypassing the need for the large record companies.

I interpret the threat, posed by gratis solutions, as a disruptive technology on its own. As Christensen (1997) explains, we can speak of a technology being disruptive if it is onslaught forces established companies with considerable former investments on their shoulders to alter their business models, while creating lucrative new opportunities for fast-moving start-up companies. Digital information wants to be free and there are no feasible means to prevent this. On-going litigation for the shutdown of servers carrying pirated music as in the case with the music industry, is more an excuse for changing the course of business events, trying to plug holes of a huge dam that is already at the brink of bursting. At present, there are countless Internet set-ups whose business model is based explicitly on offering free music, free photos and many other genres of free information to the visitor, and recouping their expenditures through selling advertising inventory and customer behavioural information. With each passing day, a new, more belligerent company emerges with no fees and with a low-to no-margin model. On the Internet, success often means that someone is already selling what you sell for cheaper.

Not only technologies can be disruptive but business models, too. Internet companies find in gratis solutions a highly leveraged way to do things better. When analysing an Internet business, there is a single metric, or tool, that represents a leveraged power. This metric, conversion rate, measures the number of visitors who come to a particular Web site, within a particular period, divided into the number of people who take action on that site (purchase, register, leave a trace behind, proffer their behavioural data). Conversion rate measures many aspects of a Web site, and a strong conversion rate offers true leverage to the site owner.

The interaction between the advertisement and the consumer are often more complicated than measurements like click-through. This is because conversion 
rate incorporates the total user experience, and advertising metrics alone do not. If a run-of-site is going to convert visitors who click through to it from an ad, they are likely to get 60 percent of the response in the first half-hour. Nevertheless, taking action is crucial for most business models that are predicated on numbers of visitors. The Internet has become a quick turn-around medium, which makes it ideal for the post-impression and post-click conversions and repeat conversions and subsequently for the usual quid-pro-quo of the Gratis Economy. It confirms that the Web is very interactive and a very active advertising medium.

\section{TOWARDS POLICYMAKING ON THE GRATIS ECONOMY}

When juxtaposing the toll free part and the commercial part of cyberspace there are some dynamics to observe. On the one hand, I am forced to diagnose assaults, a knowledge grab or enclosure. This is the case with what is called data mining and the unfortunate practice of commerce in personally identifiable data. At the same time, mushrooming gratis solutions raise their handsome head in many new pockets all over cyberspace. There seems to be an ultimate balance. The availability of public goods is an anthropological constant in every segment of the economy, including the digital economy. As the size and volume of publicly provided private goods is always in flux, I do not see yet an easy method to a thorough (real time) estimate or measurement. What belongs to the public domain in one country and one moment, may easily change over time and regions. The essence of policymaking would be to preserve this duality over time. A "tragedy of the commons" would arise when a common resource was degraded by over use as in cases of ocean fisheries, urban roads, air and water. Whenever a public good (or "bad" as in the case of road congestion) does not have an owner to manage the resource through usage restrictions and/or fees, there are inadequate incentives for individual users to restrict usage in excess of capacities. There seems to be a mechanism of the invisible hand type that upholds the main proportions, excluding the option to overdrive the free of charge solutions.

The preservation of pockets in the online world with a non-profit character and the overall growth in the Gratis Economy - with no entry fee other than our attention $^{25}$ - is predicated on pending social innovations. The current industry's

25 The duration spent by the perusal or glimpsing of an ad impression, is not much less than the customary time an experienced medical practitioner devotes to arrive at, or adopt a therapy, or the clinical professor devotes at bedside to make a judgement over the referral of a junior doctor on a patient's condition in hospitals. This indicates that this sort of virtual "entry fee" is certainly not negligible. 
self-regulation is to be complemented by (1) solving the privacy challenge posed by invasions of precision marketing; and (2) standing up against the knowledge grabbing threat against the status quo of the informational commons.

\section{REFERENCES}

Allen, Ch. (1999): Technology for Anonymity: Names by other Nyms. The Information Society, 15(2).

The Annenberg Public Policy Center's: “The Internet and The Family 2000" Survey. Full report: http://www.appcpenn.org/finalrepor fam.pdf

Arms, W.Y. (2000): Economic models for open access publishing. iMP Magazine, March 22, 2000. Online at: http://www.cisp.org/imp/march 2000/03 00arms.htm

Arnett, N. (1998): The Internet and the antinet, Mirrored in Replika 29, March 1998, Budapest.

Barbrook, R. (1998): The hi-tech gift economy. Nettime, http://www.nettime.org

Boulding K. and Pfaff, M. (1973): Introduction to the Series on Grants Economics. University of Colorado.

Brian, A. (1996): Increasing returns and the new world of business. Harvard Business Review, July.

Burroughs, W. (1986): The Naked Lunch. London: Paladin.

Castells, M. (1998): The information age: economy, society and culture; Information technology and global capitalism, in Giddens, A. and Hutton, W. (eds): On the Edge: Essays on a Runaway World. London, 2000.

Christensen, C. M. (1997): The Innovator's Dilemma. Harvard Business School Press.

The CSTB Report, (1999): Being Fluent with Information Technology. Report of the Computer Science and Telecommunications Board, National Research Council, Washington D.C.

The eAdvertising Report of April 12, 1999.

eAdvertising Report Tidbit, 1999., archives of I-Advertising, online at: http://internetadvertising.org

EMRC (Electronic Media Research Council) Minimum Standards for Electronic Media Rating Research 1983.

The Forrester Report (1999): online at: http://www.forrester.com/ER/Press/Release/ 0,1769,158, FF.html

Gunther, M. (1999): The TROUBLE WITH WEB ADvertising. Fortune, Vol. 139, No. 7, April 12.

Kania, D. (1998): Internet World Guide to One-To-One Web Marketing. New York: John Wiley.

Kannan, P. K., Chang, A. M. and Whinston, A. B. (1998): Marketing information on the I-Way. Communications of the ACM, 41: 3 .

Kelen, A. (2001): The Gratis Economy. Central European University Press, forthcoming.

Kolakowski, L. (1997): Mini-Wyklady o Maxi Sprawach. Krakow: Znak. (Hungarian edition: Europa, 1998.)

Lebrecht, N. (1996): When the Music Stops - Managers, Maestros and Corporate Murder of Classical Music. London: Simon \& Schuster.

Litan, R. and Swire, P. (1997): Non of Your Business. Ohio State University Press.

NSTIA 1999, Falling through the Net: The digital divide, online at: http://www.ntia.doc.gov/ ntiahome/fttn99/contents.html

O'Reilly, T. (1999): How the Web was almost won. Salon Magazine, Nov. 16. http://www. salon.com/tech/feature/1999/11/16/microsoft_servers 
Orlikowski, W. (1999): The truth is not out there: An enacted view of the digital economy. Conference on the Digital Economy, Washington, D.C. http://mitpress.mit.edu/UDE/ orlikowski.rtf

The Second Belgian National Survey, New Media LDV BATES Ad Agency, February 1999.

Shapiro, A. (1999): The control revolution: How the internet is putting individuals in charge and changing the world we know. Public Affairs.

Valovic, Thomas S. (2000): Digital Mythologies: The Hidden Complexities of the Internet. New Brunswick: Rutgers University Press. 
